\title{
Multiple Breath Washout Is Feasible in the Clinical Setting and Detects Abnormal Lung Function in Infants and Young Children with Cystic Fibrosis
}

\author{
Mirjam Stahla, c Cornelia Joachim ${ }^{a} \quad$ Kerstin Blessing $^{a} \quad$ Susanne Hämmerling ${ }^{a}$ \\ Olaf Sommerburga, c Philipp Latzin ${ }^{d}$ Marcus A. Mall ${ }^{a-c}$ \\ ${ }^{a}$ Division of Pediatric Pulmonology and Allergy and Cystic Fibrosis Center, Department of Pediatrics, ${ }^{\text {b }}$ Department \\ of Translational Pulmonology, and 'Translational Lung Research Center (TLRC), German Center for Lung Research \\ (DZL), University of Heidelberg, Heidelberg, Germany; ${ }^{d}$ Division of Respiratory Medicine, Department of Pediatrics, \\ University Children's Hospital of Bern, Bern, Switzerland
}

For editorial comment see p. 353

\section{Key Words}

Lung clearance index . Pulmonary function test .

Cystic fibrosis lung disease $\cdot$ Infants $\cdot$ Preschool children

\begin{abstract}
Background: Cystic fibrosis (CF) lung disease starts in the first months of life often before the onset of clinical symptoms. Multiple breath washout (MBW) detects abnormal lung function in infants and young children in the laboratory setting. Objective: The aim of this study was to determine the feasibility of MBW in 0- to 4-year-old children with CF and non-CF controls in the clinical setting. Methods: Fourteen children with CF (mean age $1.3 \pm 1.0$ years) and 26 agematched non-CF controls were sedated with chloral hydrate and MBW was performed with sulfur hexafluoride. Results: MBW measurements were successful in 27 of 40 children (67.5\%). The mean lung clearance index ( $\mathrm{LCl}$ ) was significantly higher in CF patients compared to non-CF controls ( $p=$ 0.006). Further, the frequency of elevated $\mathrm{LCl}(\mathrm{z}$-score $>1.96$ ) was significantly increased in CF patients compared to controls $(p=0.0003)$. Conclusions: We conclude that MBW is feasible and sensitive to detect abnormal lung function in infants and young children with CF in the clinical setting.
\end{abstract}

(c) 2014 S. Karger AG, Basel (c) 2014 S. Karger AG, Basel

0025-7931/14/0875-0357\$39.50/0

\section{Introduction}

Chronic obstructive lung disease with airway mucus obstruction, polymicrobial infection, and neutrophilic inflammation leading to progressive lung damage with bronchiectasis remains the main cause of morbidity and mortality in patients with cystic fibrosis (CF) $[1,2]$. Evidence from recent studies suggests that $\mathrm{CF}$ lung disease starts very early in the first months of life even in infants with CF who were diagnosed by newborn screening (NBS) and treated in specialized centers, and that lung disease is initially clinically 'silent' without overt symptoms in the majority of CF patients [3-5]. CT studies have demonstrated that a substantial fraction of infants with CF have morphological abnormalities consistent with obstructive lung disease such as air trapping, airway wall thickening, and bronchiectasis, and bronchoalveolar lavage studies have shown that these structural abnormalities are associated with early neutrophilic inflammation $[5,6]$. Consistent with these results, lung function testing using multiple breath washout (MBW) or the raised volume rapid thoracoabdominal compression technique showed abnormal lung function with ventilation inhomogeneity, hyperinflation and airflow obstruction in a subgroup of infants with CF diagnosed by NBS $[3,4,7,8]$.

\section{KARGER}

E-Mail karger@karger.com

www.karger.com/res
Marcus A. Mall, MD

Division of Pediatric Pulmonology and Allergy and Cystic Fibrosis Center Department of Pediatrics and Department of Translational Pulmonology Translational Lung Research Center, University of Heidelberg, Im Neuenheimer Feld 430 DE-69120 Heidelberg (Germany), E-Mail Marcus.Mall@ med.uni-heidelberg.de 
These results highlight the need for sensitive noninvasive endpoints that detect lung abnormalities during routine clinical follow-up to identify individual presymptomatic infants and young children with CF who may benefit from early therapeutic interventions [9].

MBW with assessment of the lung clearance index (LCI) is a noninvasive pulmonary function test that can be performed at any age in tidal breathing and does not require forced breathing maneuvers [10]. An abnormal LCI reflects ventilation inhomogeneity due to airway pathology, suggesting MBW as a suitable noninvasive outcome measure of early CF lung disease. In preschool children with CF, the LCI has been shown to be more sensitive for detecting early lung disease than spirometry [11-13], and recent studies have demonstrated the feasibility of the MBW technique in children 4 years or older in the outpatient setting $[14,15]$. In infants and young children with CF, MBW has been shown to be feasible and sensitive for detecting abnormal lung function in laboratory settings $[3,4]$; however, information on its performance in the routine clinical setting during an annual check-up in a pediatric CF center remains limited.

In this study, we therefore evaluated the feasibility and technical success rates of MBW in a CF center without prior experience with this technique. MBW was performed in sedated infants and young children with and without CF. Furthermore, we determined the ability of MBW measurements to detect abnormal lung function in individual CF patients in this age group in the clinical setting.

\section{Material and Methods}

\section{Subjects}

In this prospective cross-sectional study, MBW testing was offered to all children with CF younger than 4 years of age who were admitted to our CF center for an annual check-up from April to November 2012 and MBW measurements were performed as part of the general clinical work flow. The diagnosis of CF in all participating children was based on a positive family history $(n=3)$, positive CF NBS $(n=8)$, or clinical symptoms characteristic of CF ( $n=$ 3 ), as well as increased sweat $\mathrm{Cl}^{-}$concentrations, detection of 2 disease-causing mutations in the CFTR gene, and/or detection of abnormal CFTR function in rectal biopsies as previously described $[16,17]$. The clinical characteristics of the CF patients including age and gender, and their CFTR genotypes are provided in table 1 and online supplementary table 1 (for all online suppl. material, see www.karger.com/doi/10.1159/000357075). The non-CF control group was recruited from age-matched infants and young children (table 1) who obtained a routine diagnostic MRI scan in sedation for various indications, as detailed in the online supplementary material (online suppl. table 2), but showed no evidence of lung dis- ease. Anthropometric data of $\mathrm{CF}$ and non-CF children are provided in table 1. z-scores for weight, height, and BMI were derived from reference values of healthy children in Germany $[18,19]$. All participating children were naive to the performance of MBW measurement. The parents of all of the children completed a questionnaire on the respiratory symptoms of their child and the family history of smoking and allergic or pulmonary diseases. Exclusion criteria for all children were: a respiratory infection within 3 weeks and coexisting cardiac, renal, or neuromuscular conditions or lung disease of prematurity. This study was approved by the Ethics Committee of the University Hospital Heidelberg. Parents obtained detailed information and gave their signed informed consent.

\section{Tidal Breathing Analysis and the MBW Test}

MBW measurements were not established at our CF center before the start of this study. A physician (M.S.) and a pulmonary function technician (C.J.) from our team were trained in the MBW technique at the Inselspital Bern, Switzerland, a center specialized in pulmonary function testing in infants [20], and measurements in Heidelberg were performed under the supervision of an external expert (P.L.). All children included in this study were investigated following the same clinical work flow. They were admitted to our day hospital for their annual CF check-up including lung MRI studies (children with CF), or for a planned MRI (non-CF controls) for other indications (online suppl. table 2). After the clinical examination and exclusion of reasons that precluded sedation (e.g. a current respiratory tract infection), all children were sedated with oral or rectal chloral hydrate $(100 \mathrm{mg} / \mathrm{kg}$ body weight, maximum dose $2 \mathrm{~g}$ ) as per guidelines [21, 22] approximately $30 \mathrm{~min}$ before the scheduled MRI study, and they were continuously monitored by pulse oximetry. After induction of sleep, children were transported in their bed to the radiology department for the MRI study, which took between 30 and $45 \mathrm{~min}$. All children who were asleep after the MRI $(\mathrm{n}=36)$ were subsequently brought to the lung function laboratory, where measurements of tidal breathing and $\mathrm{MBW}$ were performed, with examination times between 20 and $45 \mathrm{~min}$. All children returned to the day hospital afterwards. About one third of the children woke up during transportation from the lung function laboratory to the day hospital, another third woke up during the first hour after the end of the MBW measurement, and the last third slept longer, but no child had to stay overnight due to sedation.

Tidal breathing and MBW testing were performed using a commercially available mainstream ultrasonic flowmeter (Exhalyzer ${ }^{\circledR}$ D; Eco Medics AG, Duernten, Switzerland) with sulfur hexafluoride (SF6) as the tracer gas [3] as previously described, with all children tested in a supine position $[3,4,20]$. Dead space reducers were used according to the children's body size and the manufacturer's recommendations. A face mask was chosen according to the size of the child's face (size 1-3). After normalization of breathing, tidal breathing was recorded for at least $5 \mathrm{~min}$ to detect a minimum of 100 breaths to measure the tidal volume (VT) and respiratory rate (RR). A minimum of 2 (ideally 3-5) washin/ washout curves were saved but only recordings that met the acceptability criteria were used to determine the LCI [10]. In brief, the acceptability criteria were defined as: absence of a leak, sighs, hiccoughing, swallowing, or arousal and a difference in FRC of less than $10 \%$ in relation to the lower value of the other curves. The LCI was determined via dedicated data acquisition and analysis software (WBreath, version 2; ndd Medical Technologies, Zürich, 
Table 1. Clinical characteristics of the study population

\begin{tabular}{|c|c|c|c|c|}
\hline & $\begin{array}{l}\text { Non-CF } \\
(n=26)\end{array}$ & $\begin{array}{l}\text { CF } \\
(n=14)\end{array}$ & $95 \% \mathrm{CI}$ & $\mathrm{p}$ value \\
\hline Males, n (\%) & $19(73.1)$ & $9(64.3)$ & - & 0.72 \\
\hline Mean age $\pm S D$, years & $1.9 \pm 1.2$ & $1.3 \pm 1.0$ & -1.4 to 0.2 & 0.12 \\
\hline Range & 0.2 to 4.0 & 0.2 to 3.2 & & \\
\hline Weight $\mathrm{z}$-score & $-0.0 \pm 1.1$ & $-0.2 \pm 1.2$ & -0.9 to 0.6 & 0.61 \\
\hline Height z-score & $-0.7 \pm 1.7$ & $-0.3 \pm 1.6$ & -0.8 to 1.5 & 0.53 \\
\hline BMI z-score & $0.3 \pm 1.3$ & $-0.2 \pm 1.0$ & -1.3 to 0.3 & 0.23 \\
\hline F508del/F508del, n (\%) & - & $6(42.9)$ & - & - \\
\hline Pancreatic insufficiency, n (\%) & - & $9(64.3)$ & - & - \\
\hline \multicolumn{5}{|l|}{ Basis for diagnosis ${ }^{\mathrm{a}}$} \\
\hline NBS, n (\%) & - & $11(78.6)$ & - & - \\
\hline Positive family history, n (\%) & - & $3(21.4)$ & - & - \\
\hline Respiratory symptoms, n (\%) & - & $2(14.3)$ & - & - \\
\hline Failure to thrive, $\mathrm{n}(\%)$ & - & $4(28.6)$ & - & - \\
\hline Gastrointestinal symptoms, n (\%) & - & $6(42.9)$ & - & - \\
\hline \multicolumn{5}{|l|}{ Detection of airway pathogens ${ }^{b}$} \\
\hline $\begin{array}{l}\text { Staphylococcus aureus } \\
\text { Ever, n (\%) }\end{array}$ & - & $7(50.0)$ & - & - \\
\hline Currently, n (\%) & - & $3(21.4)$ & - & - \\
\hline $\begin{array}{l}\text { Haemophilus influenza } \\
\text { Ever, } \mathrm{n}(\%)\end{array}$ & - & $7(50.0)$ & - & - \\
\hline Currently, n (\%) & - & $5(35.7)$ & - & - \\
\hline $\begin{array}{l}\text { Pseudomonas aeruginosa } \\
\text { Ever, } \mathrm{n}(\%)\end{array}$ & - & $0(0.0)$ & - & - \\
\hline Currently, n (\%) & - & $0(0.0)$ & - & - \\
\hline
\end{tabular}

Complete genotype information for all children with CF is provided in online supplementary table 1. ${ }^{\mathrm{a}} \mathrm{Mul}-$ tiple answers are possible. ${ }^{b}$ Detection of more than one pathogen is possible.

Switzerland); the infant temperature model was used for measurements in all children [23]. For analysis, only the results of children with at least 2 successful washout curves fulfilling the quality criteria were used.

\section{Statistical Analysis}

Data were analyzed using SPSS version 20.0 (SPSS Inc., Chicago, Ill., USA). Absolute LCI values were transformed into zscores. An abnormal LCI was defined as being outside the range of the mean LCI + 1.96 SD from non-CF controls. For categorical data, groups were compared using Fisher's exact test and for continuous data comparisons were made using an unpaired Student's $\mathrm{t}$ test. $\mathrm{p}<0.05$ was considered statistically significant.

\section{Results}

\section{MBW Is Feasible in Sedated Infants and Young Children in the Clinical Setting}

MBW was offered to a total of 40 infants and young children, i.e. 14 with an established diagnosis of $\mathrm{CF}$ and 26 age-matched non-CF controls (table 1). MBW mea- surements were integrated into the routine clinical work flow during the annual check-ups of CF patients or the diagnostic workup for various indications in non-CF controls. All children had a normal clinical examination of the lungs and the upper airways at the time of investigation. There was no difference in age, gender, or nutritional status (weight, height, and BMI) between the CF and non-CF groups (table 1). Most CF patients were diagnosed based on positive CF NBS, resulting in a mean age at diagnosis of 2 months. CF pathogens (Staphylococcus aureus and Haemophilus influenzae) were detected via throat and nose swabs in 8 CF patients at the time of MBW measurements, whereas 3 CF patients had never tested positive for a CF pathogen (table 1). Sedation with chloral hydrate was successful in 36 out of 40 children without any adverse effects (fig. 1; online suppl. table 3). Specifically, all children were monitored continuously by pulse oximetry and showed normal oxygen saturation $\left(\mathrm{SaO}_{2}\right)$ for the duration of the MRI and subsequent $\mathrm{MBW}$ studies. Further, potential side effects of chloral hydrate 
Table 2. Success of MBW measurements in sedated infants and young children

\begin{tabular}{|c|c|c|c|c|}
\hline & Total, n (\%) & $\begin{array}{l}\text { Mean age } \pm \text { SD (range), } \\
\text { years }\end{array}$ & Non-CF, n (\%) & $\mathrm{CF}, \mathrm{n}(\%)$ \\
\hline Studied population & $36(100)$ & $1.8 \pm 1.2(0.2-4.0)$ & $24(100)$ & $12(100)$ \\
\hline At least 2 successful washouts & $27(75.0)$ & $1.9 \pm 1.2(0.3-4.0)$ & $18(75.0)$ & $9(75.0)$ \\
\hline
\end{tabular}

Table 3. Summary of tidal breathing analysis

\begin{tabular}{lllrr}
\hline & Non-CF $(\mathrm{n}=17)$ & CF $(\mathrm{n}=9)$ & 95\% CI & value \\
\hline VT per kilogram of body weight $\mathrm{z}$-score & $0.0 \pm 1.0(-1.9$ to 1.4$)$ & $0.3 \pm 1.3(-1.3$ to 2.7$)$ & -0.6 to 1.3 & 0.47 \\
RR z-score & $0.0 \pm 1.0(-1.7$ to 2.3$)$ & $1.5 \pm 1.7(-1.5$ to 3.2$)$ & 0.1 to 2.8 & 0.03 \\
MV per kilogram of body weight z-score & $0.0 \pm 1.0(-2.6$ to 1.5$)$ & $1.5 \pm 1.7(-0.7$ to 4.2$)$ & 0.2 to 2.9 & 0.04 \\
\hline
\end{tabular}

Values are presented as means \pm SD (range) unless otherwise stated.

such as allergic reactions, ketonuria, or bradykardia were not observed in any child included in this study. MBW measurements yielded technically acceptable results with 2 or more washout curves (defined as a successful investigation) in 27 of these 36 infants and young children, resulting in an overall success rate of $67.5 \%$ (fig. 1). The main reason why MBW measurements did not meet the acceptability criteria were sighs or signs of a leak (online suppl. table 3). Overall success rates did not differ between the $\mathrm{CF}$ ( 9 of 14 children; $64.3 \%$ ) and non-CF groups (18 of 26 children; $69.2 \%)$ ( $\mathrm{p}=0.75$; fig. 1 ). In the subgroup of successfully sedated children $(\mathrm{n}=36)$, at least 1 acceptable washout curve was obtained in $91.7 \%$ of cases and the success rates of MBW measurements with 2 or more acceptable washout curves increased to $75 \%$ for both the CF and the non-CF groups (table 2). Of note, the success rate of technically acceptable MBW measurements was lower at the beginning of the study ( $\sim 60 \%$ for the first 10 measurements) and increased substantially to $\sim 80 \%$ thereafter.

\section{Tidal Breathing Is Abnormal in Infants and Young}

\section{Children with $C F$}

Assessment of tidal breathing prior to washin of the tracer gas (SF6) showed that the minute ventilation (MV) per kilogram of body weight was significantly increased in infants and young children with CF compared to nonCF controls ( $p=0.032)$ (table 3$)$. This increase in MV in the CF group was caused by an elevated RR, not by an

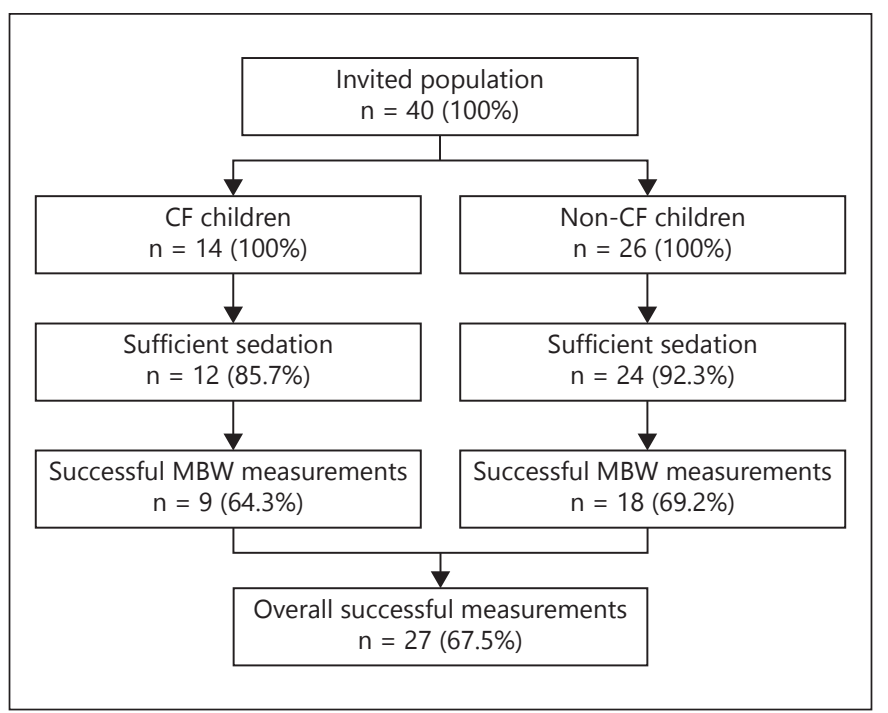

Fig. 1. Feasibility of assessment of lung function by MBW in sedated infants and young children. Total numbers and percent success rates of sufficient sedation and technically acceptable MBW measurements are provided for infants and young children with $\mathrm{CF}$ and non-CF controls.

increase in VT (table 3). Parameters of tidal breathing (VT, RR, and MV) did not correlate with age, gender, or nutritional status in the CF and non-CF groups. These results indicate that the breathing pattern is abnormal in infants and young children with CF even under sedation. 
LCI Is Increased in Infants and Young Children with CF Compared to Non-CF Controls

The mean absolute LCI in the non-CF group was $6.8 \pm$ 0.3 (range 6.4-7.3). In infants and young children with $\mathrm{CF}$, the mean LCI was slightly but significantly higher (7.6 \pm 0.6 ; range 6.7-8.6; $p=0.006$ ). Similar to the absolute LCI values, LCI $\mathrm{z}$-scores were significantly increased in patients with CF $(2.7 \pm 2.2)$ compared to non-CF controls $(0.0 \pm 1.0 ; \mathrm{p}=0.006)$ (fig. 2$)$. In the CF group, 6 out of 9 patients with CF had an elevated LCI z-score above 1.96 , whereas the remaining 3 CF patients and all non-CF controls had LCI z-scores within the normal range, resulting in a significant increase in the fraction of children with elevated LCI $\mathrm{z}$-scores in the CF group versus the non-CF control group ( $p=0.0003$ ). In both the $\mathrm{CF}$ group and the non-CF control group, the LCI z-score did not correlate with age, gender, anthropometric values, or clinical symptoms such as cough or risk factors such as parental smoking in the infants and young children included in our study.

\section{Discussion}

This study demonstrates that assessment of lung function by MBW is feasible in sedated infants and young children and that the MBW technique is sensitive for detecting early functional abnormalities in individual CF patients in the clinical routine setting. Recent results from unsedated children aged 0-4 years demonstrated that MBW can be performed with high success rates without sedation during infancy ( $69 \%)[24]$, but that the overall success rates of 2 technically acceptable MBW measurements, as recommended by current guidelines [10, 25], dropped substantially to $40 \%$ in children with CF and $23 \%$ in healthy controls [26] if toddlers and young children were included in the studies. These results indicate that use of the MBW technique to monitor lung function in unsedated children below the age of 5 years is highly limited, especially for the assessment of lung function past infancy including longitudinal MBW measurements. In our study including infants and young children with an age range of 3 months to 4 years, sedation with chloral hydrate was well tolerated without any adverse events and led to a high overall success rate of technically acceptable MBW measurements in patients with CF (64.3\%), as well as non-CF controls (69.2\%) (fig. 1). Of note, the overall success rates were somewhat impaired by insufficient sedation. In the subgroup of infants and young children who were effectively sedated, the MBW success rate was

MBW in the Clinical Setting in Infants with $\mathrm{CF}$

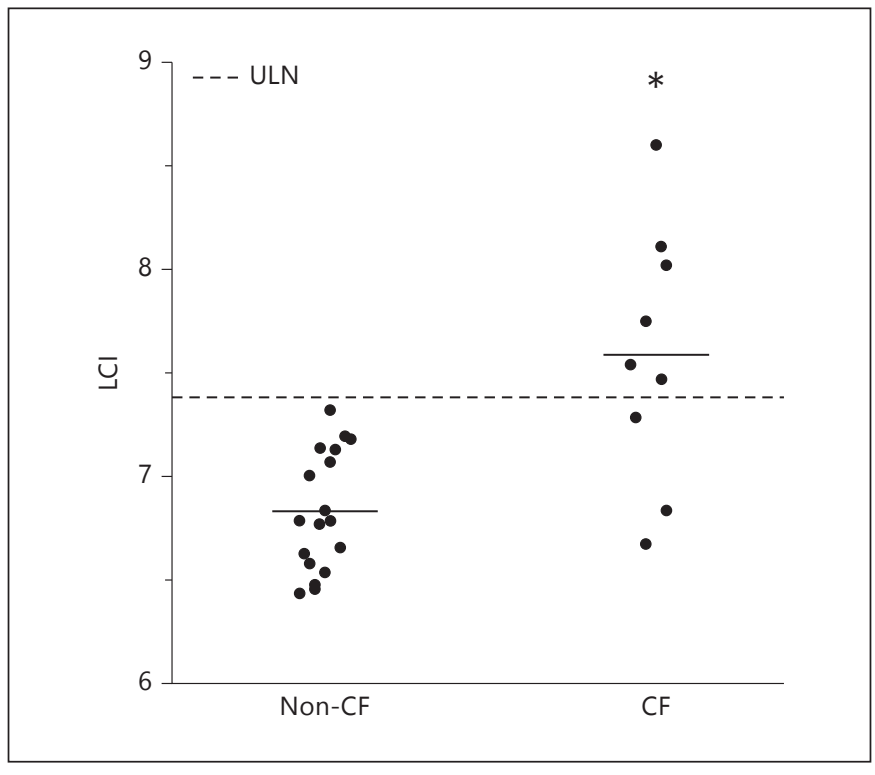

Fig. 2. MBW detects increased LCI in infants and young children with CF in the clinical setting. LCI in children with CF and non$\mathrm{CF}$ controls an upper limit of normal (ULN) of 7.4. Circles represent the measurements of single children, and solid lines represent the mean values of each group. ${ }^{*} \mathrm{p}<0.05$ compared to nonCF controls.

75\% for both the CF group and the non-CF group (table 2). The mean and distribution of the absolute LCI values and LCI z-scores obtained by our measurements were very similar to the values recently reported from sedated newborn-screened children with CF and healthy controls studied in the laboratory setting (fig. 2) [3, 4, 27]. Consistent with the results of these studies $[3,4]$, our data demonstrate that the LCI is already elevated, reflecting ventilation inhomogeneity and air trapping associated with early CF lung disease (fig. 2). The higher rate of abnormal LCI results in CF patients in our study is most likely due to our older population compared to the other published studies. Our results therefore support that the LCI obtained in sedation is a sensitive parameter for the detection and diagnostic monitoring of early lung function abnormalities in the clinical management of infants and young children with CF.

Recent studies have demonstrated that the LCI is able to detect the treatment effects of inhaled hypertonic saline and dornase alpha in pediatric patients aged 6 years or older with mild lung disease and normal spirometry $\left(\mathrm{FEV}_{1}\right.$ predicted $\geq 80 \%$ ) $[28,29]$, suggesting that the LCI may also be a sensitive noninvasive endpoint in clinical trials in infants and young children with CF. Our preclinical studies 
in a mouse model with CF-like lung disease [30, 31] demonstrated that improving airway surface dehydration by inhalation with the $\mathrm{Na}^{+}$channel blocker amiloride had significant therapeutic effects on airway mucus obstruction, inflammation, and pulmonary mortality when the treatment was started in structurally normal lungs after birth, but not in mice with established lung disease [32]. These results support the notion that therapeutic intervention may be most effective at early/presymptomatic stages, whereas therapeutic effects in established CF lung disease may be impeded by chronic disease processes including chronic mucus obstruction, inflammation, and structural damage with airway remodeling [9, 32]. Early intervention clinical trials are now feasible with the widespread implementation of CF NBS and provide a unique opportunity to develop therapeutic strategies that mitigate progression from reversible to irreversible CF lung disease. However, assessment of the treatment effects in infants and young children with CF has been hampered by the lack of established clinical trial endpoints available in older children and adults. So far, the MBW technique has not been used in multicenter intervention trials, and expertise and equipment for MBW measurements has been limited to specialized lung function laboratories. However, a monocenter add-on pilot study embedded in the first large randomized controlled trial testing the effect of $7 \%$ hypertonic saline in infants and children younger than 6 years with CF (ISIS) indicated that LCI is feasible in an interventional study at a specialized center $[33,34]$. Our results demonstrate that MBW measurement with a commercially available mainstream ultrasonic flowmeter was highly feasible in infants and young children in the clinical setting of a CF center that had no prior experience in the technique following initial training and supervision by a specialized pediatric lung function laboratory, and therefore support the practicability of LCI as an endpoint in multicenter clinical trials in this age group.
In addition to abnormal LCI, tidal breathing was also abnormal with an increased RR and MV in infants and young children with CF compared to non-CF controls (table 3). These results suggest that an abnormal breathing pattern may also be a sensitive indicator of early $\mathrm{CF}$ lung disease. Of note, abnormal tidal breathing was also observed in prior studies in newborn-screened infants with CF $[4,35]$. However, the study by Hoo et al. [4] reported an increase in VT, rather than an increased RR, in infants with CF compared to healthy controls, whereas the study by Ranganathan et al. [35] also detected an increased RR. Therefore, additional studies are required to determine the diagnostic value of abnormalities of tidal breathing in early CF lung disease.

In summary, our study demonstrates that assessment of lung function by MBW is feasible, with high success rates in sedated infants and young children with CF and healthy controls, and that the LCI is sensitive to detect early CF lung disease in the clinical setting. These results support the use of lung function testing by MBW for diagnostic monitoring of early lung disease in clinical management, and as a potential noninvasive endpoint in longitudinal observational studies on the natural history of early CF lung disease and in early intervention clinical trials in patients with CF and possibly other genetic or acquired early-onset lung diseases.

\section{Acknowledgements}

The authors thank the children and their families for their participation in this study, Chiara Abbas, Elisabeth Kieninger, and Florian Singer of the University Children's Hospital of Bern, Switzerland, for MBW training, and Carmen Pospiech for technical support. This study was supported by grants from the Dietmar Hopp Stiftung and the Deutsche Forschungsgemeinschaft (MA 2081/4-1). The funders had no role in study design, data collection and analysis, decision to publish, or preparation of this paper.

\section{References}

1 Mall M, Boucher RC: Pathogenesis of pulmonary disease in cystic fibrosis; in Bush A (ed): Cystic Fibrosis in the 21st Century. Basel, Karger, 2006, vol 34, pp 116-121.

2 Gibson RL, Burns JL, Ramsey BW: Pathophysiology and management of pulmonary infections in cystic fibrosis. Am J Respir Crit Care Med 2003;168:918-951.

-3 Belessis Y, Dixon B, Hawkins G, Pereira J, Peat J, MacDonald R, Field P, Numa A, Morton J, Lui K, Jaffe A: Early cystic fibrosis lung disease detected by bronchoalveolar lavage and lung clearance index. Am J Respir Crit Care Med 2012;185:862-873.

4 Hoo AF, Thia LP, Nguyen TT, Bush A, Chudleigh J, Lum S, Ahmed D, Lynn IB, Carr SB, Chavasse RJ, Costeloe KL, Price J, Shankar A, Wallis C, Wyatt HA, Wade A, Stocks $\mathrm{J}$ : Lung function is abnormal in 3-month-old infants with cystic fibrosis diagnosed by newborn screening. Thorax 2012;67:874881.

-5 Sly PD, Brennan S, Gangell C, de Klerk N, Murray C, Mott L, Stick SM, Robinson PJ,
Robertson CF, Ranganathan SC: Lung disease at diagnosis in infants with cystic fibrosis detected by newborn screening. Am J Respir Crit Care Med 2009;180:146-152.

6 Stick SM, Brennan S, Murray C, Douglas T, von Ungern-Sternberg BS, Garratt LW, Gangell CL, De Klerk N, Linnane B, Ranganathan S, Robinson P, Robertson C, Sly PD: Bronchiectasis in infants and preschool children diagnosed with cystic fibrosis after newborn screening. J Pediatr 2009;155:623.e1628.e1.
Stahl/Joachim/Blessing/Hämmerling/ Sommerburg/Latzin/Mall 
7 Peterson-Carmichael SL, Harris WT, Goel R, Noah TL, Johnson R, Leigh MW, Davis SD: Association of lower airway inflammation with physiologic findings in young children with cystic fibrosis. Pediatr Pulmonol 2009;44:503-511.

8 Lum S, Gustafsson P, Ljungberg H, Hulskamp G, Bush A, Carr SB, Castle R, Hoo AF, Price J, Ranganathan S, Stroobant J, Wade A, Wallis C, Wyatt $\mathrm{H}$, Stocks J: Early detection of cystic fibrosis lung disease: multiple-breath washout versus raised volume tests. Thorax 2007;62:341-347.

9 Ramsey BW, Banks-Schlegel S, Accurso FJ, Boucher RC, Cutting GR, Engelhardt JF, Guggino WB, Karp CL, Knowles MR, Kolls JK, LiPuma JJ, Lynch S, McCray PB Jr, Rubenstein RC, Singh PK, Sorscher E, Welsh M: Future directions in early cystic fibrosis lung disease research: an NHLBI workshop report. Am J Respir Crit Care Med 2012;185:887-892.

$\checkmark 10$ Beydon N, Davis SD, Lombardi E, Allen JL, Arets HG, Aurora P, Bisgaard H, Davis GM, Ducharme FM, Eigen H, Gappa M, Gaultier C, Gustafsson PM, Hall GL, Hantos Z, Healy MJ, Jones MH, Klug B, Lodrup Carlsen KC, McKenzie SA, Marchal F, Mayer OH, Merkus PJ, Morris MG, Oostveen E, Pillow JJ, Seddon PC, Silverman M, Sly PD, Stocks J, Tepper RS, Vilozni D, Wilson NM: An official American Thoracic Society/European Respiratory Society statement: pulmonary function testing in preschool children. Am J Respir Crit Care Med 2007;175:1304-1345.

11 Aurora P: Multiple-breath washout in preschool children - FRC and ventilation inhomogeneity. Paediatr Respir Rev 2006;7(suppl 1): S14-S16.

\12 Horsley AR, Gustafsson PM, Macleod KA, Saunders C, Greening AP, Porteous DJ, Davies JC, Cunningham S, Alton EW, Innes JA: Lung clearance index is a sensitive, repeatable and practical measure of airways disease in adults with cystic fibrosis. Thorax 2008;63:135-140.

13 Kraemer R, Blum A, Schibler A, Ammann RA, Gallati S: Ventilation inhomogeneities in relation to standard lung function in patients with cystic fibrosis. Am J Respir Crit Care Med 2005;171:371-378.

$>_{14}$ Singer F, Kieninger E, Abbas C, Yammine S, Fuchs O, Proietti E, Regamey N, Casaulta C, Frey U, Latzin P: Practicability of nitrogen multiple-breath washout measurements in a pediatric cystic fibrosis outpatient setting. Pediatr Pulmonol 2013;48:739-746.

15 Ellemunter H, Fuchs SI, Unsinn KM, Freund MC, Waltner-Romen M, Steinkamp G, Gappa M: Sensitivity of lung clearance index and chest computed tomography in early CF lung disease. Respir Med 2010;104:1834-1842.
16 Hirtz S, Gonska T, Seydewitz HH, Thomas J, Greiner P, Kuehr J, Brandis M, Eichler I, Rocha H, Lopes AI, Barreto C, Ramalho A, Amaral MD, Kunzelmann K, Mall M: CFTR $\mathrm{Cl}^{-}$ channel function in native human colon correlates with the genotype and phenotype in cystic fibrosis. Gastroenterology 2004;127: 1085-1095.

17 Sommerburg O, Lindner M, Muckenthaler M, Kohlmueller D, Leible S, Feneberg R, Kulozik AE, Mall MA, Hoffmann GF: Initial evaluation of a biochemical cystic fibrosis newborn screening by sequential analysis of immunoreactive trypsinogen and pancreatitis-associated protein (IRT/PAP) as a strategy that does not in volve DNA testing in a Northern European population. J Inherit Metab Dis 2010;33:S263-S271.

18 Brandt I, Reinken L: The growth rate of healthy children in the first 16 years: BonnDortmund longitudinal developmental study (in German). Klin Padiatr 1988;200:451-456.

19 Kromeyer-Hauschild K, Wabitsch M, Geller F, Ziegler A, Geiss HC, Hesse V, Hippel V, Jaeger U, Johnsen D, Kiess W, Korte W, Kunze D, Menner K, Müller M, Niemann-Pilatus A, Remer TH, Schaefer F, Wittchen HU, Zabransky S, Zellner K, Hebebrand J: Perzentile für den Body Mass Index für das Kindesund Jugendalter unter Heranziehung verschiedener deutscher Stichproben. Monatschr Kinderheilkd 2001;149:807-818.

20 Fuchs O, Latzin P, Thamrin C, Stern G, Frischknecht $P$, Singer F, Kieninger E, Proietti E, Riedel T, Frey U: Normative data for lung function and exhaled nitric oxide in unsedated healthy infants. Eur Respir J 2011;37:1208-1216.

21 American Academy of Pediatrics Committee on Drugs and Committee on Environmental Health: use of chloral hydrate for sedation in children. Pediatrics 1993;92:471-473.

22 Gaultier C, Fletcher ME, Beardsmore C, England S, Motoyama E: Respiratory function measurements in infants: measurement conditions - Working Group of the European Respiratory Society and the American Thoracic Society. Eur Respir J 1995;8:1057-1066.

23 Latzin P, Sauteur L, Thamrin C, Schibler A, Baldwin D, Hutten GJ, Kyburz M, Kraemer R, Riedel T, Frey U: Optimized temperature and deadspace correction improve analysis of multiple breath washout measurements by ultrasonic flowmeter in infants. Pediatr Pulmonol 2007;42:888-897.

24 Kieninger E, Singer F, Fuchs O, Abbas C, Frey U, Regamey N, Casaulta C, Latzin P: Longterm course of lung clearance index between infancy and school-age in cystic fibrosis subjects. J Cyst Fibros 2011;10:487-490.

-25 Robinson PD, Latzin P, Verbanck S, Hall GL, Horsley A, Gappa M, Thamrin C, Arets HG, Aurora P, Fuchs SI, King GG, Lum S, Macleod K, Paiva M, Pillow JJ, Ranganathan S, Ratjen F, Singer F, Sonnappa S, Stocks J, Subbarao P, Thompson BR, Gustafsson PM: Consensus statement for inert gas washout measurement using multiple- and single-breath tests. Eur Respir J 2013;41:507-522.
26 Bakker EM, van der Meijden JC, Nieuwhof EM, Hop WC, Tiddens HA: Determining presence of lung disease in young children with cystic fibrosis: lung clearance index, oxygen saturation and cough frequency. J Cyst Fibros 2012;11:223-230.

27 Hall GL, Logie KM, Parsons F, Schulzke SM, Nolan G, Murray C, Ranganathan S, Robinson P, Sly PD, Stick SM, Berry L, Garratt L, Massie J, Mott L, Poreddy S, Simpson S: Air trapping on chest CT is associated with worse ventilation distribution in infants with cystic fibrosis diagnosed following newborn screening. PLoS One 2011;6:e23932.

28 Amin R, Subbarao P, Jabar A, Balkovec S, Jensen R, Kerrigan S, Gustafsson P, Ratjen F: Hypertonic saline improves the LCI in paediatric patients with CF with normal lung function. Thorax 2010;65:379-383.

-29 Amin R, Subbarao P, Lou W, Jabar A, Balkovec S, Jensen R, Kerrigan S, Gustafsson P, Ratjen F: The effect of dornase alfa on ventilation inhomogeneity in patients with cystic fibrosis. Eur Respir J 2011;37:806-812.

30 Mall M, Grubb BR, Harkema JR, O’Neal WK, Boucher RC: Increased airway epithelial $\mathrm{Na}^{+}$ absorption produces cystic fibrosis-like lung disease in mice. Nat Med 2004;10:487-493.

31 Zhou Z, Duerr J, Johannesson B, Schubert SC, Treis D, Harm M, Graeber SY, Dalpke A, Schultz C, Mall MA: The ENaC-overexpressing mouse as a model of cystic fibrosis lung disease. J Cyst Fibros 2011;10(suppl 2):S172S182.

- 32 Zhou Z, Treis D, Schubert SC, Harm M, Schatterny J, Hirtz S, Duerr J, Boucher RC, Mall MA: Preventive but not late amiloride therapy reduces morbidity and mortality of lung disease in $\beta \mathrm{ENaC}$-overexpressing mice. Am J Respir Crit Care Med 2008;178:12451256.

-33 Rosenfeld M, Ratjen F, Brumback L, Daniel S, Rowbotham R, McNamara S, Johnson R, Kronmal R, Davis SD: Inhaled hypertonic saline in infants and children younger than 6 years with cystic fibrosis: the ISIS randomized controlled trial. JAMA 2012;307:2269-2277.

34 Subbarao P, Stanojevic S, Brown M, Jensen R, Rosenfeld M, Davis S, Brumback L, Gustafsson P, Ratjen F: Lung clearance index as an outcome measure for clinical trials in young children with cystic fibrosis: a pilot study using inhaled hypertonic saline. Am J Respir Crit Care Med 2013;188:456-460.

35 Ranganathan SC, Goetz I, Hoo AF, Lum S, Castle R, Stocks J: Assessment of tidal breathing parameters in infants with cystic fibrosis. Eur Respir J 2003;22:761-766.
MBW in the Clinical Setting in Infants with $\mathrm{CF}$
Respiration 2014;87:357-363 DOI: $10.1159 / 000357075$ 